\title{
Pengaruh Metode Token Economy Terhadap Aktifitas Perawatan Diri pada Pasien Defisit Perawatan Diri
}

\author{
Heppi Sasmita $^{a}$, Rizka Mahdairta $^{\mathrm{b}}$ Asterina $^{\mathrm{c}}$ \\ ${ }^{a}$ Poltekes Kemenkes Padang \\ ${ }^{\mathrm{b}}$ Mahasiswa PSIK Keperawatan \\ ${ }^{c}$ Fakultas Kedokteran Universitas Andalas \\ E-mail: heppisasmita@yahoo.com
}

\begin{abstract}
Self-care deficit is an impaired ability to perform self-care activities. Lack of self-care the result of changes in thought processes so that the ability to perform self-care activities declined. Token economy method is a modification of behavior by giving one sign/ gesture as soon as possible after each target behavior appears. This study used a pre-experimental design with pretest-posttest one group approach to patient self care deficits in the Prof. HB. Sa'anin Mental Hospital, Padang, a total of 15 people on 19 November to 9 December 2011, which aimed to determine the effect of token economy method to self-care activities. Sampling was conducted with a total sampling technique. Variable research was method token economy and self-care activities. The data collection is done by measuring the activity of the respondents self-care before and after treatment by using the observation sheet. The data analysis performed using SPSS with the Wilcoxon test. Results showed no effect of method of token economy to increase self-care activities with the results of statistical tests $p<0,05$. Prof.HB.Sa'anin Mental Hospital, Padang is expected to be able to use the method of token conomy as a means used to handling the problem of self-care deficit.
\end{abstract}

Key words: method of token economy, self-care activities

\begin{abstract}
Abstrak : Defisit perawatan diri adalah gangguan kemampuan untuk melakukan aktifitas perawatan diri. Kurangnya perawatan diri terjadi akibat adanya perubahan proses pikir sehingga kemampuan untuk melakukan aktifitas perawatan diri menurun. Metode token economy merupakan modifikasi perilaku dengan pemberian satu tanda/ isyarat sesegera mungkin setiap kali setelah perilaku sasaran muncul. Tujuan dari metode token economy ini adalah untuk meningkatkan perilaku individu yang diinginkan. Penelitian ini menggunakan rancangan preeksperimen dengan pendekatan one group pretest-posttest pada pasien defisit perawatan diri di ruang Melati Rumah Sakit Jiwa Prof. HB. Sa'anin Padang, sebanyak 15 orang pada 19 November - 9 Desember 2011 untuk mengetahui pengaruh metode token conomy terhadap aktifitas perawatan diri. Pengambilan sampel dilakukan dengan teknik total sampling. Pengumpulan data dilakukan dengan mengukur aktifitas perawatan diri responden sebelum dan setelah perlakuan dengan menggunakan lembar observasi. Analisa data dilakukan dengan uji Wilcoxon. Hasil penelitian menunjukkan ada pengaruh metode token economy terhadap peningkatan aktifitas perawatan diri dengan hasil uji statistic $\mathrm{p}<0,05$. Pihak Rumah Sakit Jiwa Prof.HB.Sa'anin Padang diharapkan agar dapat menggunakan metode token economy sebagai suatu cara yang digunakan untuk penanganan masalah defisit perawatan diri.
\end{abstract}

Kata kunci: metode token economy, aktifitas perawatan diri

Kesehatan jiwa merupakan perasaan sehat dan bahagia serta mampu mengatasi tantangan hidup, dapat menerima orang lain sebagaimana adanya serta mempunyai sikap positif terhadap diri sendiri dan orang lain. Kesehatan jiwa meliputi perasaan terhadap 
diri sendiri, perasaan terhadap orang lain, dan kemampuan dalam mengatasi persoalan hidup sehari-hari. Kesehatan jiwa merupakan bagian integral dari kesehatan, sehat jiwa sangat dibutuhkan oleh semua orang baik dalam berperilaku maupun dalam bertindak. Seseorang yang mengalami masalah dalam berperilaku dan bertindak dapat menyebabkan terjadinya gangguan jiwa (Sulizah, 2007).

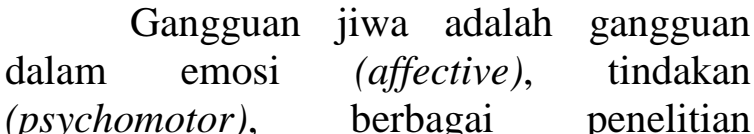
mengatakan bahwa gangguan jiwa adalah kumpulan dari keadaan keadaan yang tidak normal, baik yang berhubungan dengan fisik maupun dengan mental. Keabnormalan tersebut dibagi ke dalam dua golongan yaitu: gangguan jiwa (neurosa) dan sakit jiwa (psikosa). Keabnormalan terlihat dalam berbagai gejala yang terpenting, diantaranya adalah ketegangan (tension), rasa putus asa dan murung, gelisah, cemas, perbuatanperbuatan yang terpaksa (convulsive), hysteria, rasa lemah, tidak mampu mencapai tujuan, takut, pikiran-pikiran buruk (Iyus, 2009).

Menurut data World Health Organization (WHO), masalah gangguan kesehatan jiwa di seluruh dunia memang sudah menjadi masalah yang sangat serius. WHO (2006) menyatakan, paling tidak ada satu dari empat orang di dunia mengalami masalah mental. WHO memperkira-kan ada sekitar 450 juta orang di dunia yang mengalami gangguan kesehatan jiwa. Sementara itu, menurut Uton Muchtar Rafei, Direktur WHO Wilayah Asia Tenggara, hampir satu per tiga dari penduduk di wilayah ini pernah mengalami gangguan neuropsikiatri. Buktinya, bisa kita cocokkan dan lihat sendiri dari data survey Kesehatan Rumah Tangga (SKRT); tahun 2006 saja, di Indonesia diperkirakan sebanyak 264 dari 1.000 anggota rumah tangga menderita gangguan kesehatan jiwa.

Prevalensi gangguan kesehatan jiwa di Indonesia menurut hasil studi Bahar dkk
(2006) adalah 18,5\%, yang berarti dari 1000 penduduk terdapat sedikitnya 185 penduduk dengan gangguan kesehatan jiwa atau tiap rumah tangga terdapat seorang anggota keluarga yang menderita gangguan kesehatan jiwa. Jika hasil studi ini dapat dijadikan dasar, maka tidak dapat dipungkiri bahwa telah terjadi peningkatan angka gangguan kesehatan jiwa/gangguan emosional yang semula berkisar antara 2060 per 1000 penduduk (Yani, 2006).

Menurut Wartonah (2007) gangguan jiwa dapat terjadi dalam bentuk halusinasi, perilaku kekerasan, isolasi sosial, harga diri rendah, dan defisit perawatan diri sehingga muncul masalah penurunan aktifitas perawatan diri pada klien. Kebutuhan aktifitas perawatan diri merupakan fokus dalam asuhan keperawatan jiwa, sehingga perawat harus memiliki kemampuan dan pengetahuan cara pemenuhan kebutuhan aktifitas perawatan diri klien dengan memantau dan mengikuti perkembangan kemampuan pasien dalam melaksanakan aktifitas perawatan diri terutama pasien gangguan jiwa yang mengalami defisit perawatan diri.

Kondisi yang timbul pada saat sekarang ini adalah pada umumnya pasien gangguan jiwa yang berada di jalanan, cenderung mengalami defisit perawatan diri. Gejala yang tampak pada pasien tersebut diantaranya : pakaian klien tampak kumal, kulit klien berdaki, rambut klien acakacakan, badan klien bau, makan klien berceceran, klien $\mathrm{BAB} / \mathrm{BAK}$ disembarang tempat.

Defisit Perawatan Diri adalah gangguan kemampuan untuk melakukan aktifitas perawatan diri (mandi, berhias, toileting, makan). Dampak dari defisit perawatan diri secara fisik yaitu: gangguan integritas kulit, gangguan membrane mukosa mulut, serta gangguan fisik pada kuku, juga berdampak pada masalah psikososial seperti gangguan kebutuhan rasa nyaman, kebutuhan dicintai dan mencintai, kebutuhan harga diri, aktualisasi diri, dan gangguan interaksi sosial. Lebih jauh lagi masalah tersebut bisa menularkan berbagai 
macam penyakit kepada penghuni lain dan juga tenaga kesehatan.

Ada beberapa terapi untuk merobah gangguan perilaku klien defisit perawatan diri diantaranya: terapi kognitif, terapi keluarga, terapi lingkungan, terapi psikoreligius, terapi kelompok, terapi individu, dan terapi perilaku. Salah satu jenis terapi perilaku yang dapat digunakan disini adalah metode token economy yang merupakan sebuah prosedur modifikasi perilaku dengan menggunakan reinforcement positif yaitu pemberian satu kepingan (isyarat / tanda) sesegera mungkin setiap kali setelah perilaku sasaran muncul. Kelebihan dari metode ini adalah dapat langsung diberikan sesudah perilaku target terbentuk, dan dapat ditukarkan dengan benda bila waktu dan tempat memungkinkan, cara ini akan efektif bila diberlakukan pada sekelompok orang. Menurut Depkes (2000), pasien gangguan jiwa yang mengalami masalah defisit perawatan diri sudah dapat menunjukkan perubahan perilaku dengan lama hari perawatan 14 hari.

Berdasarkan hasil penelitian Sugianti (2005) tentang pengaruh metode token economy terhadap aktifitas perawatan diri pada pasien defisit perawatan diri di Rumah Sakit Jiwa DR.Radjiman Wediodiningrat Lawang, menyebutkan bahwa $20,5 \%$ responden dengan aktifitas perawatan diri kurang baik, 79,5\% responden dengan aktifitas perawatan diri baik. Seiring dengan hasil penelitian Saryono (2008) tentang pengaruh metode token economy terhadap aktifitas perawatan diri pada pasien defisit perawatan diri di Rumah Sakit Jiwa Dharma Sakti Jakarta Pusat menyebutkan bahwa 35,5 \% responden dengan aktifitas perawatan kurang baik, 64,5\% responden dengan aktifitas perawatan diri baik, juga dengan hasil penelitian Fresa (2006) tentang pengaruh metode token economy terhadap aktifitas perawatan diri pada pasien isolasi sosial yang mengalami defisit perawatan diri di Rumah Sakit Jiwa Mitra Menteng Abadi Jakarta Pusat menyebutkan bahwa $40,5 \%$ responden dengan aktifitas perawatan diri kurang baik, 59,5 \% responden dengan aktifitas perawatan diri baik, seiring dengan hasil penelitian Sarifah (2007) tentang pengaruh metode token economy terhadap aktifitas perawatan diri pada pasien Skizofrenia yang mengalami defisit perawatan diri di Rumah Sakit Jiwa Dharma Jaya Jakarta, menyebutkan bahwa $40,15 \%$ responden dengan aktifitas perawatan diri kurang baik, 60,85 \% responden dengan aktifitas perawatan diri baik.

Rumah Sakit Jiwa Prof. HB. Sa'anin Padang merupakan rumah sakit tipe A yang ada di kota Padang. Rumah Sakit ini mempunyai 8 ruangan, 1 ruang IGD / PICU, 1 ruangan NAPZA dan 6 ruangan diantaranya dengan pengembangan model praktek keperawatan professional (MPKP) yaitu : Anggrek, dari 5 orang pasien yang di rawat, 1 orang pasien $(20 \%)$ mengalami masalah defisit perawatan diri, Flamboyan, dari 22 orang pasien yang dirawat, 6 orang pasien $(27,27 \%)$ mengalami masalah defisit perawatan diri, Cendrawasih, dari 45 orang pasien yang di rawat, 19 orang pasien (42 $\%$ ) mengalami masalah defisit perawatan diri, Melati, dari 25 orang pasien yang di rawat, 20 orang pasien $(55,55 \%)$ mengalami masalah defisit perawatan diri, Gelatik, dari 25 orang pasien yang di rawat, 11 orang pasien (44\%) mengalami masalah defisit perawatan diri, Merpati, dari 24 orang pasien yang di rawat, 11 orang pasien (45 \%) mengalami masalah defisit perawatan diri. Keenam ruangan dengan pengembangan model praktek keperawatan professional (MPKP) tersebut, ruangan melati adalah ruangan yang paling banyak memiliki pasien dengan defisit perawatan diri. 
Berdasarkan hasil wawancara peneliti dengan kepala ruangan melati pada tanggal 16 September 2011, menyebutkan bahwa sudah dilaksanakan terapi generalis untuk mengatasi masalah perilaku klien defisit perawatan diri, namun di ruangan ini masalah defisit perawatan diri sangat menonjol. Hal ini disebabkan karena belum efektifnya pemberian terapi generalis yang diberikan oleh perawat selama ini, adapun sebuah terapi yang dapat digunakan dalam mengatasi masalah perilaku klien defisit perawatan diri yaitu terapi perilaku dengan metode token economy. Menurut Eugene (2007) metode token ekonomi ini sangat efektif digunakan mengubah perilaku klien dengan masalah defisit perawatan diri.

Survei awal yang dilakukan di ruangan melati pada tanggal 16 September 2011, gejala yang tampak pada pasien defisit perawatan diri diantaranya : badan klien bau, gigi klien kuning, rambut klien kotor dan berkutu, kuku klien panjang dan kotor, rambut klien acak-acakan, klien tidak mau mengganti pakaian, tidak berdandan. Gejala tersebut menunjukkan bahwa terganggunya aktifitas kebersihan diri dan berhias pada pasien.

Berdasarkan fenomena diatas, maka penulis merasa tertarik untuk mengetahui pengaruh metode token economy terhadap aktifitas perawatan diri pada pasien defisit perawatan diri di ruang Melati Rumah Sakit Jiwa Prof.HB.Sa'anin Padang Tahun 2012.

\section{METODE}

Jenis penelitian yang digunakan adalah rancangan Pra-Eksperimen dengan pendekatan One Group Pretest-Postest. Populasi pada penelitian ini adalah seluruh pasien dengan defisit prawatan diri di ruang Melati Rumah Sakit Jiwa Prof.HB.Sa'anin Padang. Sampel pada penelitian ini berjumlah 15 orang. Cara mendapatkan data dengan mengukur aktifitas perawatan diri responden yang terdiri dari aktifitas kebersihan diri dan berhias sebelum dan sesudah diberikan intervensi. Waktu pengumpulan data dilakukan selama 3 minggu yaitu pada hari ke 1 peneliti melakukan pretest dan pada hari ke 21 peneliti melakukan posttest. Analisa dilakukan dengan analisa bivariat menggunakan uji wilcoxon.

Pengumpulan data dilakukan selama 3 minggu yaitu sejak tanggal 19 November hingga 9 Desember 2011. Pada awalnya penelitian ini direncanakan akan dilakukan terhadap 25 orang responden. Selama pelaksanaan intervensi, 10 orang responden menolak/mengundurkan diri karena pasien mengalami halusinasi berat sehingga responden berjumlah 15 orang.

Pengumpulan data baik pretest maupun posttest dilakukan oleh peneliti sendiri tetapi pemberian perlakuan (intervensi) dengan memberikan metode token economy dilakukan oleh peneliti namun dibantu oleh petugas di ruang Melati Rumah Sakit Jiwa Prof.HB.Sa'anin Padang dengan terlebih dahulu melatih dan memberikan informasi mengenai pedoman pelaksanaan intervensi.

Setelah dilakukan Uji normalitas terhadap data yang ditemukan dengan menggunakan uji normalitas Shapiro-Wilk dihasilkan nilai $\mathrm{p}$ value $<0,05$ maka distribusi data aktifitas perawatan diri responden defisit perawatan diri adalah tidak normal sehingga uji hipotesis yang digunakan adalah uji Wilcoxon.

Dari Tabel 1, dapat diketahui bahwa responden mengalami peningkatan aktifitas kebersihan diri sebelum diberikan intervensi sampai setelah diberikan intervensi. Responden yang mendapatkan nilai 0 pada aktifitas kebersihan diri berarti responden yang tidak ada satupun melakukan aktifitas kebersihan diri, namun setelah diberikan intervensi responden mengalami peningkatan nilai menjadi 5 yang berarti responden sudah melakukan lima point untuk aktifitas kebersihan diri meliputi: mandi, menggosok gigi, mencuci rambut, menggunakan sabun di saat mandi, dan memotong 
Tabel 1.

Distribusi frekuensi responden berdasarkan aktifitas kebersihan diri dan berhias pada pasien defisit perawatan diri sebelum dan sesudah diberikan intervensi

\begin{tabular}{|c|c|c|c|c|c|c|}
\hline \multirow[b]{2}{*}{$\begin{array}{c}\text { No. } \\
\text { Responden }\end{array}$} & \multicolumn{3}{|c|}{ Kebersihan Diri } & \multicolumn{3}{|c|}{ Berhias } \\
\hline & $\begin{array}{c}\text { Sebelum } \\
\text { Perlakuan } \\
\text { (Pretest) }\end{array}$ & $\begin{array}{c}\text { Setelah } \\
\text { Perlakuan } \\
\text { (Posttest) }\end{array}$ & Perubahan & $\begin{array}{c}\text { Sebelum } \\
\text { Perlakuan } \\
\text { (pretest) }\end{array}$ & $\begin{array}{c}\text { Setelah } \\
\text { Perlakuan } \\
\text { (Posttest) }\end{array}$ & Perubahan \\
\hline 1 & 0 & 5 & 45 & 0 & 2 & 42 \\
\hline 2 & 0 & 5 & 5 & 0 & 1 & 1 \\
\hline 3 & 0 & 5 & 5 & 0 & 2 & 2 \\
\hline 4 & 2 & 4 & 2 & 2 & 3 & 1 \\
\hline 5 & 0 & 3 & 3 & 0 & 2 & 2 \\
\hline 6 & 0 & 3 & 3 & 0 & 2 & 2 \\
\hline 7 & 0 & 3 & 3 & 0 & 2 & 2 \\
\hline 8 & 0 & 2 & 2 & 0 & 2 & 2 \\
\hline 9 & 4 & 4 & 40 & 3 & 3 & $\uparrow_{0}$ \\
\hline 10 & 0 & 2 & 2 & 0 & 2 & 2 \\
\hline 11 & 0 & 3 & 3 & 0 & 2 & 2 \\
\hline 12 & 0 & 3 & 3 & 0 & 1 & 1 \\
\hline 13 & 3 & 5 & 2 & 3 & 3 & $\uparrow 0$ \\
\hline 14 & 0 & 3 & 3 & 0 & 2 & 2 \\
\hline 15 & 0 & 2 & 42 & 0 & 2 & 2 \\
\hline
\end{tabular}

Pada aktifitas berhias diketahui bahwa responden mengalami peningkatan aktifitas berhias dari sebelum diberikan intervensi sampai setelah diberikan intervensi. Responden yang mendapatkan nilai 0 pada aktifitas berhias berarti responden yang tidak ada satupun melakukan aktifitas berhias, namun setelah diberikan intervensi responden mengalami peningkatan nilai menjadi 2 yang berarti responden sudah melakukan 2 point untuk aktifitas berhias meliputi: menyisir rambut, dan mengganti pakaian.

\section{Tabel 2.}

Pengaruh metode token economy terhadap aktifitas kebersihan diri dan berhias pada pasien defisit perawatan diri di ruang Melati Rumah Sakit Jiwa Prof.HB.Sa'anin Padang Tahun 2012

\begin{tabular}{lllll}
\hline Variabel & Hasil & $\mathbf{N}$ & $\mathbf{Z}$ & $\mathbf{P}$ \\
\hline $\begin{array}{l}\text { Posttest aktifitas } \\
\text { Kebersihan diri- }\end{array}$ & Post < Pre & 0 & $-3,358$ & 0,01 \\
$\begin{array}{l}\text { Pretest aktifitas } \\
\text { Kebersihan diri }\end{array}$ & Tetap & 14 & & \\
\hline Total & 1 & 15 & & \\
\hline $\begin{array}{l}\text { Posttest aktifitas } \\
\text { Berhias }\end{array}$ & Post < Pre & 0 & $-3,358$ & 0,01 \\
$\begin{array}{l}\text { Aktifitas } \\
\text { berhias }\end{array}$ & Tetap & 13 & & \\
& & 2 & & \\
\hline
\end{tabular}


Dari Tabel 2, diketahui bahwa hasil uji statistik didapatkan nilai $\mathrm{p}<0,05$ (nilai $\mathrm{p}$ $=0,01)$ maka dapat disimpulkan terdapat perbedaan bermakna aktifitas kebersihan diri pada pasien defisit perawatan diri setelah diberikan metode token economy dan diketahui bahwa hasil uji statistik didapatkan nilai $\mathrm{p}<0,05$ (nilai $\mathrm{p}=0,01$ ) maka dapat disimpulkan terdapat perbedaan bermakna aktifitas berhias pada pasien defisit perawatan diri setelah diberikan metode token economy.

Hasil penelitian yang dilakukan pada klien yang mengalami defisit perawatan diri di ruang Melati RSJ.Prof.HB.Sa'anin Padang tahun 2012, didapatkan hasil bahwa pada tabel 1 responden mendapatkan nilai 5 pada aktifitas kebersihan diri. Hal ini disebabkan karena telah terjadi peningkatan jumlah nilai aktifitas kebersihan diri dari sebelum diberikan intervensi sampai setelah diberikan intervensi. Apabila dikaitkan dengan karakteristik responden, pada umumnya responden berkerja. Orang yang bekerja lebih memperhatikan perawatan dirinya dibandingkan dengan orang yang tidak bekerja karena pada orang yang bekerja lebih memperhatikan penampilan.

Peningkatan aktifitas kebersihan diri pada pasien disebabkan karena klien diberikan pujian saat pasien melakukan aktifitas kebersihan diri. Pujian yang diberikan disertai pemberian reward pada pasien. Adanya reward yang diberikan pada pasien dapat memotivasi pasien untuk melakukan kebersihan diri. Reward yang diberikan berupa perlengkapan mandi seperti sabun, sampo, pasta gigi, sikat gigi sehingga membuat pasien termotivasi dari dalam dirinya untuk melakukan aktifitas kebersihan diri dan dapat meningkatkan aktifitas kebersihan diri pada pasien setelah diberikan pujian disertai dengan reward.

Naning (2009) menyatakan

pemberian pujian dan reward yang diberikan pada pasien dapat membantu meningkatkan aktifitas kebersihan diri. Demikian juga dengan teori Eugene (2007) menyatakan aktifitas kebersihan diri dapat dilakukan jika pasien mendapatkan pujian dari perawat ataupun lingkungan sekitarnya.

Penelitian yang dilakukan oleh Septiabudi (2006) menyatakan bahwa pasien mengalami peningkatan aktifitas kebersihan diri setelah diberikan reward yang disertai dengan pujian untuk melakukan aktifitas kebersihan diri.

Meningkatnya kebersihan diri pada pasien bisa disebabkan oleh pujian berupa reinforcement positif yang diberikan oleh perawat maupun keluarga. Pujian yang diberikan pada pasien dapat memotivasi klien dari dalam dirinya untuk melakukan kebersihan diri. Selain itu pemberian reward pada pasien dapat meningkatkan kebersihan diri pasien, dimana pasien merasakan perasaan senang setelah diberikan reward. Reward yang diberikan pada pasien dapat mendorong klien untuk melakukan kebersihan diri.

Hasil uji statistik dengan menggunakan uji wilcoxon didapatkan aktifitas kebersihan diri sebelum dan sesudah diberikan intervensi adalah nilai $\mathrm{p}=$ $0,00 \quad(\mathrm{p}<0,05)$, maka dapat disimpulkan terdapat pengaruh yang bermakna pada pemberian metode token economy terhadap aktifitas kebersihan diri pada pasien defisit perawatan diri. Dengan demikian Ho ditolak.

Metode token economy merupakan suatu cara yang diberikan guna untuk meningkatkan aktifitas kebersihan diri pasien. Metode ini diberikan segera setelah perilaku sasaran muncul. Token yang diberikan di dalam penelitian ini berupa tanda bintang (*). Dengan pemberian tanda bintang $\left(^{*}\right)$, pasien merasakan senang karena diberikan suatu penghargaan. Semakin banyak tanda bintang (*) yang 
terkumpul, pasien merasakan ada suatu kebanggaan dari dalam dirinya karena berhasil mendapatkan tanda bintang (*) tersebut dengan penuh perjuangan. Selain mendapatkan tanda bintang (*) pasien juga mendapatkan reward setelah berhasil melakukan aktifitas kebersihan diri. Reward yang diberikan kepada pasien berupa perlengkapan mandi. Dengan adanya perlengkapan mandi tersebut lebih menumbuhkan motivasi pasien untuk melakukan aktifitas kebersihan diri.

Sulizah (2007) menyatakan metode token economy lebih efektif untuk meningkatkan aktifitas kebersihan diri. Token economy dapat digunakan sebagai penguat yang bertahan lama karena dapat diberikan segera sesudah suatu perilaku yang diinginkan muncul. Dan dapat ditukarkan dengan reward. Kemudian Tarwoto (2008) menyebutkan salah satu cara untuk mengatasi gangguan aktifitas kebersihan diri adalah dengan melakukan metode token economy.

Menurut Soetarlinah Soekadji (2007) definisi token economy adalah pemberian satu tanda / isyarat segera mungkin setiap kali setelah perilaku sasaran muncul. Tanda-tanda ini nantinya dapat ditukarkan dengan reward. Seiring dengan teori yang dikemukakan oleh (Sugianty, 2007) menyatakan bahwa token economy cocok diberikan pada pasien yang mengalami gangguan aktifitas kebersihan diri.

Seiring dengan teori yang dikemukakan oleh (Sadock, 2007) token economy dapat membantu untuk meningkatkan perilaku pasien yang diharapkan terutama pasien rawat inap yang mengalami masalah gangguan aktifitas kebersihan diri.

Penelitian Stevi (2006) menyatakan bahwa pasien mengalami aktifitas kebersihan diri baik setelah diberikan metode token economy. Demikian juga dengan penelitian yang dilakukan oleh Jayanti (2007) setelah diberikan metode token economy, pasien mengalami aktifitas kebersihan diri baik.
Meningkatnya aktifitas kebersihan diri pada pasien bisa disebabkan karena pemberian metode token economy yang efektif digunakan untuk meningkatkan aktifitas kebersihan diri yaitu dengan pemberian tanda bintang (*). Semakin banyak tanda bintang yang terkumpul, pasien menjadi senang dan bangga akan kemampuan yang ada pada dirinya sehingga dapat meningkatkan rasa percaya diri pada pasien untuk melakukan aktifitas kebersihan diri. Oleh karena itu metode token economy sangat cocok digunakan untuk pasien rawat inap dengan masalah gangguan aktifitas kebersihan diri.

\section{KESIMPULAN DAN SARAN}

Berdasarkan hasil penelitian yang dilakukan tentang pengaruh metode token economy terhadap aktifitas perawatan diri pada pasien defisit perawatan diri di ruang Melati Rumah Sakit Jiwa Prof.HB.Sa'anin Padang Tahun 2012 , maka dapat diambil kesimpulan sebagai berikut: Setelah dilakukan metode token economy didapatkan hasil bahwa responden yang melakukan aktifitas kebersihan diri sebanyak 14 orang dan responden yang melakukan aktifitas berhias sebanyak 13 orang. Terdapat perbedaan bermakna antara aktifitas kebersihan diri dan aktifitas berhias sebelum diberikan metode token economy dengan sesudah diberikan metode token economy

Ada beberapa hal yang dapat disarankan dalam penelitian ini, yaitu: Bagi Institusi Pendidikan Metode token economy cukup efektif untuk meningkatkan aktifitas perawatan diri karena memotivasi pasien dari dalam dirinya untuk melakukan aktifitas perawatan diri yang disertai dengan pemberian pujian dan reward pada pasien, Bagi Institusi Pelayanan Kesehatan Memberikan informasi khususnya untuk ruangan rawat inap agar menggunakan metode token economy untuk meningkatkan aktifitas perawatan diri pada pasien defisit perawatan diri, namun ada hambatan dalam melakukan metode ini yaitu keterbatasan sarana dan prasarana untuk melakukan 
metode token economy dan disarankan pada institusi pelayanan agar dapat melengkapi kekurangan sarana dan prasarana untuk menunjang aktifitas perawatan diri pasien yang terdiri dari aktifitas kebersihan diri dan berhias, Bagi Riset Penelitian Sebagai data dasar dan pembanding untuk peneliti selanjutnya agar dapat mengembangkan metode token economy ini pada kasus yang lain yang lebih difokuskan pada masalah aktifitas makan dan toileting pasien dengan jumlah sampel yang berbeda disertai dengan metode penelitian yang berbeda.

\section{DAFTAR PUSTAKA}

Sulizah, (2001). Pendekatan holistik pada gangguan jiwa. Jakarta: FKUI.

Eugene \& Klamen, D. (2007). Psyhiartry therapeutics. New York: Raven Press.

Sadock \& Kaplan. (2007). Synopsis psikiatri jilid 2. Jakarta: EGC.

Sugianti. (2008). Kesehatan jiwa kurang diperhatikan. Diakses pada tanggal 1 Agustus 2011 dari http://syehaceh.wordpress.com

Yani. (2010). Synopsis of psychiatry. Jakarta: EGC. Diakses padatanggal $1 \mathrm{Ag}$ ustus 2011dari http://id.wikipedia.org/wiki

Iyus, Y. (2009). Keperawatan jiwa. Bandung: RefikaAditama. 